vessel rotate in an anti-clockwise direction' seems principally designed to avoid the problem of ambiguity which may arise because of differing interpretations of radar information leading to disagreement, on both vessels, about the correct application of the manouvring rules.

This ambiguity - though it must be said that this is not an essential problem as it can be solved by the application of the Sector Rule 2 -may be easily solved by the step-by-step manœuvre in a way covering any kind of vessel using radar in a reduced visibility situation. This method of solution is proposed by the author in another contribution in the Forum section of this Journal. In the case of good visibility the criterion could be that vessel $A$ with the other $B$ on her starboard must initiate action in accord with the manouvring rules. And that vessel B must take action as soon as she knows what vessel $A$ is doing. So, the case could arise, if vessel A is hampered, where her conduct would be contrary to the general manouvring rules. If this should occur vessel B must, and would be able to, adjust her actions to the situation. On the other hand, Captain Thompson's Steering Rules cannot cover all the situations involving sailing vessels, and he must give them a special rule (Rule 4) which may contradict his Rule I 6.

The idea of increasing speed, as found in Rule 2(c), seems an unwise solution to be specified in the Rules because it is well known that, in general, the reserve over normal speed is small. The agreement established in Rule $2(\mathrm{e})$ also seems unwise.

Finally, it seems that Captain Thompson, with his Rule 5(c), intends to cope with the problem of two or more vessels simply by establishing that: 'At the junction of routes, vessels shall proceed round them in an anti-clockwise direction.' In fact this is the direction implied in my tactics for vessel group manœuvres, 2 but in order to arrange this multi-vessel situation safely, it is necessary to establish the limits of the range at which a vessel becomes a part of a group, the classification of peripheral and internal vessels, and the Sector Rule, as essential to common safety while using radar in reduced visibility.

\title{
REFERENCES
}

1 García-Frías, J. (1960). Anti-collision radar sectors. This Journal, 13, 316.

2 Garcia-Frias, J. (1965). The sector rules and the collision problem. This Journal, 18, 141 .

3 Garcia-Frías, J. (1970). The revision of the Rules. This Journal, 23,7 I.

\section{The Collision Problem and Manœuvring by Stages}

\section{Rear-Admiral J. García-Frías}

WHEN the danger of collision between vessels occurs, the proper interpretation of radar information will indicate that, with respect to the manouvring rules, any avoiding action should always be positive. However, it is well known that radar 
information is not always properly interpreted. Misinterpretation may cause a situation to be assessed as ambiguous. This, in turn, may produce disagreement, on both vessels, about how the rules should be correctly applied. To solve this difficulty, some authors propose communication between the vessels. Others think the avoiding action of any vessel should automatically be such that the sight line rotates in the anti-clockwise direction. (The latter suggestion results in a port-to-port passing whilst the vessels cross with a port bearing from the aspect of the overtaking ship.) Complications may arise from either proposal.

The usual adverse effects arising from an ambiguous situation are well known. They include such possibilities as one vessel turning to port and the other to starboard, i.e. the vessels turning inward toward each other. Or, the ships may keep their respective courses on the same side of the sight line at very similar speeds.

Since radar gives range accurately enough for all manœuvres by stages, it is easy to establish that the initial turns to starboard should be undertaken at, for example, a 2.5-mile range while initial turns to port should begin at a 2-mile range. The initial turns to starboard ought to be substantial enough to produce a clear change in bearing from the aspect of the other vessel.

Thus, if both vessels turn to starboard at a range of 2.5 miles, the problem is solved. However, if only one vessel turns in this direction, then the change of bearing from the other vessel's aspect will be such that she, too, must turn to starboard at a range of two miles. This may be qualified in the case in which vessel $A$, seeing another vessel $B$ to starboard, herself turns to starboard at a range of 2.5 . If this occurs, then vessel B may or may not need to turn to starboard, as well. However, if vessel A, finding vessel B on her starboard side and thinking the bearing is opening, does not alter course at the 2.5 -mile range then it is important that vessel B clearly understands this. For, although the bearing has not changed - as it would have had vessel A altered course to starboard substantially-vessel B, at a range of 2 miles, may still safely alter course to port.

Manouvring by stages may also be considered a satisfactory solution to the problem if hampered vessels, proceeding at normal speeds, are involved in an encounter. When sailing vessels and other hampered vessels of low speed encounter unhampered vessels fitted with radar, the hampered vessels should be included in the class of 'vessels not fitted with radar' and treated as such under my Sector Rule. 1

The case may arise of large vessels or deep-draught vessels which, though having normal speeds, have limited manœuvrability. When this occurs-and the vessel that under normal circumstances would turn substantially to starboard in an intervallic manœuvre cannot do this easily-then, if the other vessel is not hampered, she should turn to port at a range of 2 miles. The range in this case may be reduced to 2 miles, as opposed to 2.5 miles if the first vessel had been able to veer to starboard, for the bearing will not be changing as clearly as in the former case.

\section{REFERENCE}

1 García-Frías, J. (1965). The sector rule and the collision problem. This Journal, 18, 141 . 